\title{
Nexus Between Tourism, Environmental Degradation, and Economic Growth: Evidence From Non-Linear ARDL and Causality Estimation
}

Muhammad Amir ( $\sim$ ma.arain824@gmail.com)

University of the Punjab https://orcid.org/0000-0003-1782-2265

Muhammad Siddique

University of the Punjab

Kamran Ali

University of the Punjab

Azaz Ali Ather Bukhari

University of the Punjab

Naila Kausar

University of the Punjab

\section{Research Article}

Keywords: Tourism demand, environmental degradation, economic growth, Pakistan, non-linear autoregressive distributed lag

Posted Date: June 2nd, 2021

DOl: https://doi.org/10.21203/rs.3.rs-488768/v1

License: (c) (1) This work is licensed under a Creative Commons Attribution 4.0 International License. Read Full License 


\title{
Nexus between Tourism, Environmental Degradation, and Economic Growth: Evidence from Non-
} Linear ARDL and Causality Estimation

\author{
Muhammad Amir \\ Corresponding Author \\ Research Associate, Department of Commerce, \\ University of the Punjab, Gujranwala Campus. \\ Email: ma.arain824@gmail.com \\ ORCID ID: 0000-0003-1782-2265
}

Dr. Muhammad Siddique

Associate Professor, Department of Commerce, University of the Punjab, Gujranwala Campus.

Email: dr.siddique@pugc.edu.pk

\section{Kamran Ali}

Lecturer, Department of Commerce, University of the Punjab, Gujranwala Campus.

Email: kamran.ali@pugc.edu.pk

\section{Azaz Ali Ather Bukhari}

Lecturer, Department of Banking and Finance, University of the Punjab, Gujranwala Campus

Email: azaz.bukhari@pugc.edu.pk

\section{Naila Kausar}

Adjunct Lecturer, Department of Commerce, University of the Punjab, Gujranwala Campus.

Email: nailaazeem0@gmail.com

\section{(1)}



Linear ARDL and Causality Estimation

\section{Abstract}

The purpose of this study is to assess the asymmetric associations of environmental degradation, and economic growth with Pakistan's tourism demand. To fulfil this purpose, "non-linear autoregressive distributed lag" (NARDL) modelling was performed on the time series data collected from Pakistan for 26 years. The unit root test, co-integration test, long-run estimation, and NARDL estimations were applied to the data to generate findings. The present study revealed the presence of significant asymmetric associations between environmental degradation and tourism demand and economic growth and tourism demand. It is found that the increase and decrease in economic growth cause the tourism demand of Pakistan to increase. Results further indicate that the increase in environmental degradation in Pakistan causes its tourism demand to reduce. The current study tends to be theoretically significant and practically beneficial for Pakistan's policymakers. It will help them realize the role of economic growth of the country and environmental degradation in shaping Pakistan's tourism demand and thus help them develop and implement better policies for the growth of the tourism sector.

Keywords: Tourism demand, environmental degradation, economic growth, Pakistan, non-linear autoregressive distributed lag

\section{Introduction}

Environmental degradation (ED) is increasingly affecting the world, and the number of environmental concerns is increasing around the world. The literature examining and discussing the ED links it with various sectors among which the tourism sector entails the particular importance. It is because the tourism sector involves various activities associated with emissions, wastage, exploitation of natural resources etc. that give rise to ED (Balsalobre-Lorente, Driha, Shahbaz, \& Sinha, 2020; Haseeb \& Azam, 2020; Raza et al., 2021; Raza, Sharif, Wong, \& Karim, 2017; Sharif et al., 2020). The issue of ED becomes more alarming when it comes to developing countries such as Pakistan because they have limited resources, techniques, and capital to control ED. Therefore, researchers need to examine how the ED and tourisms in the developing countries are linked. The tourisms sector of Pakistan has experienced the robust growth during last few decades and it is still growing and contributing largely to the country's GDP and employment (Manzoor, Wei, \& Asif, 2019; Rehman, Ma, Irfan, Ahmad, \& Traore, 2020).

The tourism sector around the world has emerged as a fast-growing sector during last couple of decades, which led various countries to enhance their tourism infrastructure as per their respective tourism demand. Tourisms is regarded as the pivotal factor to keep the country and economy on the path of growth because it contributes to the country by improving the per capita income, inflow of money, tax revenues, employment, country's infrastructure, economic activities, and foreign investments (Balcilar, Van Eyden, Inglesi-Lotz, \& Gupta, 2014; Jalil, Mahmood, \& Idrees, 2013). It is reported by "The United Nations World Tourism Organization" (NWTO) that the industry of tourism will become the largest industry of the world by 2050 with respect to GDP. Given the contribution of this sector to tax revenues, business activity, employment, export revenues etc. this sector is regarded as the key factor in economic development of the country (Adedoyin, Nathaniel, \& Adeleye, 2021; Paramati, Alam, \& Chen, 2017; Sokhanvar, 2019). However, the tourism demand tends to be influenced by a number of macroeconomic, political, social, technological, and other factors including the macroeconomic policies, social trends, trade and visa rules, geopolitical issues, bilateral relations and trade relations with other countries etc. The tourism demand needs to be estimated by the investors, governments, and other stakeholders before making investments in infrastructure including roads, transport, hotels, bridges, shopping malls, and other tourism fields (Martins, Gan, \& Ferreira-Lopes, 2017; Shafiullah, Okafor, \& Khalid, 2019; Tavares \& Leitao, 2017). Therefore, factors need to be identified and explained that are related to the tourism demand in the country. Although the existing literature provides insights into different factors influencing 
the tourism demand but a strong need still exists in the literature to discover and explain some of the key factors deriving the tourism demand in the country.

Among other factors, the ED is now becoming a hot topic in terms of its influence on the tourism demand. The increasing environmental concerns around the world have made tourists and people more environmentally consciousness so, the countries having the high ED are likely to be less attractive for tourism (Chung, Pan, Zou, \& Liu, 2018; Otrachshenko \& Bosello, 2017; Zhang, Khan, Kumar, Golpîra, $\&$ Sharif, 2019). Another factor, which is supposed to be related to the demand in the country is economic growth (EG) because the high EG and development tend to enhance the tourism demand in the country. It means that when the economy of country growth, it comes in better position to enhance its infrastructure and tourism sectors and thus, make its tourism sector more attractive and enhance tourism demand in the country (Isik, Dogru, \& Turk, 2018; Kim, Lee, \& Mjelde, 2018). Similarly, researchers including Balaguer and Cantavella-Jorda (2002), Masood Sheikh (2018), Pavlic, Svilokos, and Tolic (2015), and Meo, Chowdhury, Shaikh, Ali, and Masood Sheikh (2018) regard the exchange rate as one of the responsible factors determining the tourism demand. For instance, the deflation of local currency reduces the general tourism expenses for foreign tourists/people who have strong currency and want to visit the country. Therefore, the deflation of local currency can result in the increased inflow of tourists in country and thus, the increased tourism demand.

Hence, the literature provides insights that tourism demand, economic growth (EG), and ED are interrelated. However, the literature seems to be insufficient in explaining the econometric estimations and non-linear relationships efficiently due to providing mixed and general findings. For example, some of the past studies such as Muhtaseb and Daoud (2017) present the unidirectional association from tourism to growth, some studies such as He and Zheng (2011) present the unidirectional connexion from EG to tourism, some studies such as Tang and Ozturk (2017) present the bidirectional association between tourism and EG, and some studies such as Pavlic et al. (2015) suggest that there does not exist any causality between EG and tourism. Therefore, the mixed findings and evidence about their association in this existing literature posit the need for empirically explaining these relationships and estimations. The current study intends to contribute to the literature in this regard by explaining the relationships of ED and EG with tourism demand through non-linear ARDL and causality estimation in context of Pakistan. It will add value to the literature and practice and would help policymakers of Pakistan to realize the role of EG as well as ED in shaping the tourism demand.

\section{Literature Review}

ED is the worsening of environment through diminution of natural properties i.e. water, air, soil. ED tends to share the strong linkage with the tourism demand. Balsalobre-Lorente et al. (2020) has investigated ED and its effect on tourism and globalization in developed countries. It was revealed through the empirical evidence that the increased globalization of economies and ED have ominously reduced tourism. High ED is said to be the cause of energy shortage and promotion of renewable sources. Zhang et al. (2019) has steered a study in Thailand to check the relationship of ED, tourism, and logistic \& transportation related operations. ARDL statistical method was used to check the relationship, which concluded that ED and inbound tourism are negatively correlated. Findings of the mentioned study suggested for the implementation of green practices in country so that the influence of ED on inbound tourism can be reduced.

Raza et al. (2017) has examined the impact of tourism progression on environmental disrepair in hightourism oriented countries (UK, USA) and in low-tourist-arrival countries. "Maximal Overlap Discrete Wavelet Transforms (MODWT), wavelet co-variance, correlation, Continuous Wavelet Power, Coherence Spectrum, and Wavelet-Based Granger Causality Analysis" were applied to find the association between tourism and ED. They suggested that tourism has significantly increased ecological degradation in long period of time, which means that with the increase in tourism, ED also increases and vice versa. Raza et al. (2021) has studied ED and tourism with an aim to discover the inverse relationship 
between them. Results of "Panel Smooth Transition Regression (PSTR)" revealed that relationship between tourism and ED was non-linear and the increase in tourism demand decreased ED.

The affiliation between global warming and tourism development was also investigated by Haseeb and warming which is caused from excessive transportation inclination (an environmental hazardous activity). "Fully Modified Ordinary Least Squares (FMOLS) Method of Panel and Dumitrescu Hurlin Panel Causality Tests" were applied for detailed analysis of the variables. Results revealed that $\mathrm{CO}_{2}$ emission and tourism are negatively connected. A number of past studies have emphasized that ED and tourism are absolutely correlated e.g. (Haseeb, Hassan, Azam, \& Suryanto, 2018; Meo et al., 2018; Naradda Gamage, Hewa Kuruppuge, \& Haq, 2017). Contribution of vacation industry is deemed to be a value addition to the beauty of the country whereas contamination is also one of the most major environmental glitches faced by the global economy.

Ahmad, Draz, Su, and Rauf (2019) conducted an explanatory study to check the nexus concerning tourism and ecological deterioration in Southeast Asian countries i.e. Vietnam, Indonesia and Philippines. They argued that opportunity cost of tourism with respect to environmental deterioration is high which has the long-lasting effects on the economy as well. The "Zivot-Andrews Unit Root Test" and the "Gregory-Hansen Test for Robustness" were applied by them to check the association between these two variables. Study revealed the negative impact of tourism for Indonesia and Philippine whereas positive impact for Vietnam. Anser et al. (2020) also examined the growth in tourism and ED with the mediating role of "information and communication technology" (ICT) in United Nations. The mentioned study aimed at eradicating poverty, preserving natural environment, and ensuring prosperity. They discussed that air and road transportation is the means of pollution which is affected by tourism development. The mentioned study showed that carbon emission adversely affects the environment which is caused by high inbound tourism activities. Hence, the review of literature and different past studies about the relationship between ED and tourism shows that a portion of the literature presents the positive relationship between ED and demand of tourism, but another portion presents the negative relationship among tourism and environmental dilapidation. So, researchers need to conduct further empirical studies to reach harmonized results about theses estimations and causalities.

The relationship of EG and tourism is a double-edged sword. It means that ED is the opportunity cost for real EG and high inclination of tourism. Leitão and Balsalobre-Lorente (2021) examined the relationship among tourism, economic development, and renewable energy. They suggest that the increasing trend of tourism significantly increases the economic development of the country. "United Nations world tourism organization (UNWTO)" advocated maintainable tourism activities without deteriorating environment. Higher NI, per capita income, and GDP growth rate are the driving variables for economic development and inbound tourism are one of the sources of income of a country. "Panel data Random Effects (RE), Panel Dynamic Least Squares (PDLS), and Panel Granger Causality Test" applied to check the relationship equilibrium between the variables showed that tourism is positively interrelated with EG. Fareed, Meo, Zulfiqar, Shahzad, and Wang (2018) also investigated the non-linear relationship between tourism and EG in Thailand using past 27 years of data of tourism and EG and applying NARDL model. They suggest that tourism as a powerful engine of world's economy which draws favourable results upon economy of Thailand. However, they found that early 20's data showed negative relation while past 10 years data showed coherence of tourism with EG.

Samimi, Sadeghi, and Sadeghi (2011) also suggested that, EG and tourism are strongly associated in emerging countries. "P-VAR Approach" used on the data of GDP and tourism of 20 developing countries revealed that tourism has significant positive impact on EG of the developing countries. They suggested that there is bilateral association and significant long lasting connection between EG and tourism progression. According to the data showed by "World Tourism Organization (WTO)", tourism-driven economic rate is up to $7.8 \%$ in developing countries for the year 2005-2010. Suresh and Senthilnathan 
(2014) also performed a study to check the relationship between EG and tourism demand in Sri Lanka. Tourism is fast growing business in Sri Lanka and its impact on the economy is vibrant. Checking the casual relationship, they originate that there is a uni-directional and two-pronged relationship between EG and tourism. Tourism-led EG strategies are the most important implications for policy makers of Sri Lanka. Another study conducted by Suresh and Senthilnathan (2014) also checked the dynamic relationship between tourism, fiscal growth, and environmental quality. "Econometric Test Robust to Heterogeneity and Cross-Sectional Dependence Test" were applied by them on data revealed that EG significantly encourages tourism. In addition to these studies, a number of past studies have highlighted that EG and tourism are correlated e.g. (Brida, Gómez, \& Segarra, 2020; Nissan, Galindo, \& Méndez, 2011).

Some studies suggest that tourism is uni-directional to EG. For example, Risso, Barquet, and Brida (2010) examined this unidirectional relationships in Trentino-Alto Adige/Sidtirol which is a province of northeast Italy neighbouring Austria and Switzerland and has found that the tremor in tourism disbursement yields a constructive influence on economic progression. Eugenio-Martin, Martín Morales, and Scarpa (2004) has examined the impact of high GDP rate and per capita national income on tourism development in Latin America. Panel data approach and the Arellano-Bond estimator used by them revealed that medium income countries/underdeveloped countries need high social, economic, and GDP per capita as the inbound tourism is conditional to GDP and EG. Hence, the literature about the growthtourism nexus tends to provide the mixed insights so, the relationship between them needs to be further checked and empirically explained.

\section{Methodology}

The current study has been conducted with the data of Pakistan. The current study involves five key variables among which ED and EG are two independent variables, tourism demand is the only dependent variable, and inflations and exchange rate are two control variables. The annual data of all these five variables for Pakistan has been collected for 26 years for the time span of 1995-2020. The data has been extracted from databases of world trade organization (WTO) and world development indicators (WDI). Tourism demand is measured as the "number of visitor arrivals" in the country, ED is measured as the $\mathrm{CO} 2$ emissions in "metric tons per capita", EG is measured as the "gross domestic product per capita", inflation is measured as the "consumer price index", and the exchange rate is measured as the ratio of domestic currency per dollars. All these variables and their measuring units along with the source have been presented in table 1 .

Table 1: Variables and Measurements

\begin{tabular}{lcc}
\hline Variable & Measurement & Source \\
\hline Environmental degradation (ED) & $\mathrm{CO} 2$ emissions metric tons per capita & WDI \\
Economic growth (EG) & GDP per capita & WDI \\
Tourism demand (TD) & Number of visitor arrivals & WDI, WTO \\
Inflation & Consumer price index & WDI \\
Exchange rate (EXR) & Domestic currency per dollars & WDI \\
\hline
\end{tabular}

The current study estimates the asymmetric relationships between variables because the positive and negative change in ED, EG, inflation, and exchange rate do not cause the systematic change in the tourism demand. Therefore, the current study applies non-linear "auto regressive distributed lag" (ARDL) model to check their asymmetric association. The long-run associations of ED, EG, inflation, and exchange rate with tourism demand have been estimated through following linear equation:

$$
T D_{t}=\beta_{0}+\beta_{1} \mathrm{ED}_{t}+\beta_{2} \mathrm{EG}_{t}+\beta_{3} \mathrm{EXR}_{t}+\beta_{4} \mathrm{INF}_{t}+u_{t}
$$

Where TD, ED, EG, EXR, and INF represent the tourism demand, ED, EG, exchange rate, and inflation respectively. Given the nonlinearities in the time series data, the current study has been carried out in nonlinear setting. The reasons for conducting the study in non-linear setting may be: 
Therefore, to assess the asymmetric relationships between variables, following non-linear model has been used:

$$
T D=f\left(E D^{+}, E D^{-}, E G^{+}, E G^{-}, E X R^{+}, E X R^{-}, I N F^{+}, I N F^{-}\right)
$$

Following the footsteps of empirical studies such as Dhaoui and Bacha (2017) and Meo et al. (2018), the asymmetric relationship between ED, EG, inflation, exchange rate, and tourism demand has been estimated through following model:

$$
\begin{gathered}
T D_{t}=\theta_{0}+\theta_{1}\left(\mathrm{ED}_{t}^{+}\right)+\theta_{2}\left(\mathrm{ED}_{t}^{-}\right)+\theta_{3}\left(\mathrm{EG}_{t}^{+}\right)+\theta_{4}\left(\mathrm{EG}_{t}^{-}\right)+\theta_{5}\left(\mathrm{EXR}_{t}^{+}\right)+\theta_{6}\left(\mathrm{EXR}_{t}^{-}\right)+ \\
\theta_{7}\left(\mathrm{INF}_{t}^{+}\right)+\theta_{8}\left(\mathrm{INF}_{t}^{-}\right)+\varepsilon_{t}
\end{gathered}
$$

In equation (3), $\theta_{i}$ presents the long-run parameters. The asymmetric impact of ED, EG, EXR, and inflation on tourism demand is assimilated by positive variations and negative variations. The equation (1) only provides the estimation of long-run effects while the short-run effects are estimated through following error correction model:

$$
\begin{gathered}
\Delta \mathrm{TD}_{\mathrm{t}}=\gamma_{0}+\sum_{k=1}^{m} \gamma_{1 \mathrm{k}} \Delta \mathrm{TD}_{\mathrm{t}-\mathrm{k}}+\sum_{k=1}^{m} \gamma_{2 \mathrm{k}} \Delta \mathrm{ED}_{\mathrm{t}-\mathrm{k}}+\sum_{k=1}^{m} \gamma_{3 \mathrm{k}} \Delta \mathrm{EG}_{\mathrm{t}-\mathrm{k}}+\sum_{k=1}^{m} \gamma_{4 \mathrm{k}} \Delta \mathrm{EXR}_{\mathrm{t}-\mathrm{k}}+\sum_{k=1}^{m} \gamma_{5 \mathrm{k}} \Delta \mathrm{INF}_{\mathrm{t}-\mathrm{k}} \\
+\lambda_{1} \mathrm{TD}_{\mathrm{t}-1}+\lambda_{2} \mathrm{ED}_{\mathrm{t}-1}+\lambda_{3} \mathrm{EG}_{\mathrm{t}-1}+\lambda_{4} \mathrm{EXR}_{\mathrm{t}-1}+\lambda_{5} \mathrm{INF}_{\mathrm{t}-1}+\mu_{t}
\end{gathered}
$$

Equation (4) represents the error correction approach providing the short-run as well as long-run coefficients. The differenced variables $(\Delta)$ represent the short-run coefficients and $\lambda$ represents the longrun coefficients. It is assumed in equation (4) that asymmetric relationship exists between proposed variables. To fulfil the prime aim of the current study i.e. to see the asymmetric impacts of ED, EG, EXR, and inflation on tourism demand, following non-linear co-integrating equation is used. The decomposition regression is as follow:

$$
a_{t}=\theta^{+} b_{t}^{+}+\theta^{-} b_{t}^{-}+\mu_{t}
$$

In this equation, $\theta^{+}$and $\theta^{-}$are linked with the long-run coefficients while $b_{t}$ indicates the vector of regressor that are decomposed as follow:

$$
b_{t}=b_{t}^{+}+b_{t}^{-}(5)
$$

They are independent variables that are disintegrated into partial addition of positive and negative variations. The partial sums of positive and negative deviations in ED, EG, EXR, and inflation are indicated by following equations:

$$
E D^{-}=\sum_{i=1}^{t} \Delta E D_{i}^{-}=\sum_{i=1}^{t} \min \left(\Delta E D_{i}, 0\right)
$$




$$
E G^{+}=\sum_{i=1}^{t} \Delta E G_{i}^{+}=\sum_{i=1}^{t} \max \left(\Delta E G_{i}, 0\right)
$$

$$
E G^{-}=\sum_{i=1}^{t} \Delta E G_{i}^{-}=\sum_{i=1}^{t} \min \left(\Delta E G_{i}, 0\right)
$$

$$
E X R^{+}=\sum_{i=1}^{t} \Delta E X R_{i}^{+}=\sum_{i=1}^{t} \max \left(\Delta E X R_{i}, 0\right)
$$

$$
E X R^{-}=\sum_{i=1}^{t} \Delta E X R_{i}^{-}=\sum_{i=1}^{t} \min \left(\Delta E X R_{i}, 0\right)
$$

$$
I N F^{+}=\sum_{i=1}^{t} \Delta I N F_{i}^{+}=\sum_{i=1}^{t} \max \left(\Delta I N F_{i}, 0\right)
$$

$$
I N F^{-}=\sum_{i=1}^{t} \Delta I N F_{i}^{-}=\sum_{i=1}^{t} \min \left(\Delta I N F_{i}, 0\right)
$$

265

266

Hence, these variables will be displaced in equation (4) to formulate the non-linear ARDL (NARDL) model as follow:

$$
\begin{aligned}
\Delta \mathrm{TD}_{\mathrm{t}}=\theta+\sum_{k=1}^{m} & \theta_{\mathrm{k}} \Delta \mathrm{TD}_{\mathrm{t}-\mathrm{k}}+\sum_{k=1}^{m} \theta_{\mathrm{k}} \Delta \mathrm{ED}^{+}{ }_{\mathrm{t}-\mathrm{k}}+\sum_{k=1}^{m} \theta_{\mathrm{k}} \Delta \mathrm{ED}^{-}{ }_{\mathrm{t}-\mathrm{k}}+\sum_{k=1}^{m} \theta_{\mathrm{k}} \Delta \mathrm{EG}^{+}{ }_{\mathrm{t}-\mathrm{k}}+\sum_{k=1}^{m} \theta_{\mathrm{k}} \Delta \mathrm{EG}^{-}{ }_{\mathrm{t}-\mathrm{k}} \\
& +\sum_{k=1}^{m} \theta_{\mathrm{k}} \Delta \mathrm{EXR}^{+}{ }_{\mathrm{t}-\mathrm{k}}+\sum_{k=1}^{m} \theta_{\mathrm{k}} \Delta \mathrm{EXR}^{-}{ }_{\mathrm{t}-\mathrm{k}}+\sum_{k=1}^{m} \theta_{\mathrm{k}} \Delta \mathrm{INF}^{+}{ }_{\mathrm{t}-\mathrm{k}}+\sum_{k=1} \theta_{\mathrm{k}} \Delta \mathrm{INF}^{-}{ }_{\mathrm{t}-\mathrm{k}} \\
& +\lambda_{1} \mathrm{TD}_{\mathrm{t}-1}+\lambda_{2} E D^{+}{ }_{\mathrm{t}-1}+\lambda_{3} E D^{-}{ }_{\mathrm{t}-1}+\lambda_{4} E G^{+}{ }_{\mathrm{t}-1}+\lambda_{5} E G^{-}{ }_{\mathrm{t}-1}+\lambda_{6} E X R^{+}{ }_{\mathrm{t}-1} \\
& +\lambda_{7} E X R^{-}{ }_{\mathrm{t}-1}+\lambda_{8} I N F^{+}{ }_{\mathrm{t}-1}+\lambda_{9} I N F^{-}{ }_{\mathrm{t}-1} \\
& +\mu_{t}
\end{aligned}
$$

The bounds testing approach has been applied to above-mentioned model as the inclusion of decomposed positive and negative series of ED, EG, EXR, and inflation makes the current model NARDL. To ensure that all variables were stationary whether $\mathrm{I}(0)$ or $\mathrm{I}(1)$, the "unit root test" was applied because the NARDL approach does not require series to be necessarily stationary at the first order (Meo et al., 2018; Panopoulou \& Pittis, 2004).

\section{Results and Discussion}

The current study estimates the asymmetric effects of ED, EG, inflation, and exchange rate on tourism demand. First of all, the descriptive analysis is performed to check the normality, adequacy, and appropriateness of all series. Table 2 presents the results of descriptive analysis, which show that the data of tourism demand, EG, ED, EXR, and inflation is adequate because there is no outlier in the data of these variables. 
Table 2: Descriptive Statistics

\begin{tabular}{llllll}
\hline Indicators & TD & ED & EG & EXR & INF \\
\hline Mean & 6.565 & -0.142 & 1.266 & 4.277 & 1.949 \\
Median & 6.694 & -0.100 & 1.465 & 4.190 & 2.035 \\
Maximum & 7.550 & 0.095 & 2.022 & 5.064 & 3.011 \\
Minimum & 5.911 & -0.386 & -0.010 & 3.455 & 0.916 \\
Std. Dev. & 0.401 & 0.140 & 0.550 & 0.418 & 0.560 \\
Skewness & 0.032 & -0.135 & -0.930 & -0.008 & -0.240 \\
Kurtosis & 2.765 & 1.863 & 3.030 & 2.320 & 2.033 \\
Jarque-Bera & 0.065 & 1.479 & 3.747 & 0.501 & 1.261 \\
Probability & 0.968 & 0.477 & 0.154 & 0.778 & 0.532 \\
Sum & 170.686 & -3.692 & 32.919 & 111.210 & 50.665 \\
Sum Sq. Dev. & 4.024 & 0.490 & 7.574 & 4.374 & 7.849 \\
Observations & 26 & 26 & 26 & 26 & 26 \\
\hline
\end{tabular}

Table 2 further shows that the skewness statistics of all five variables range from -1 to +1 and kurtosis against each variable is also $<3$ so, the normality of the data is proved. The normality of the current data is further evident through Jarque-Bera and p-value against it because it is $>0.05$ for all five variables of the study. Hence, these results indicate that the current data is normal and adequate so, it can be used for the main analysis. After checking the descriptive statistics of variables, the "unit root test" is applied to check the stationarity of the data because the series need to be stationary for applying ARDL modeling. In this regard, the ADF and "Phillips-Perron" (PP) tests are applied for unit root analysis. Table 3 presents the results of this analysis.

295 Table 3: Unit Root Tests

\begin{tabular}{llllll}
\hline Variable & TD & ED & EG & EXR & INF \\
\hline Test Type & \multicolumn{5}{c}{ ADF (augmented Dickey-Fuller unit root test) } \\
\hline At Level & -0.2690 & -0.6575 & $-3.4698^{*}$ & -0.6393 & -2.1348 \\
At First Difference & $-3.3046^{* *}$ & $-5.5751^{* *}$ & $-6.4682^{* *}$ & $-3.7806^{* *}$ & $-5.0459^{* *}$ \\
\hline Test Type & & \multicolumn{5}{c}{ PP (Phillips-Perron unit root test.) } \\
\hline At Level & -0.2690 & -0.6220 & $-3.4698^{*}$ & -0.6801 & -2.1847 \\
At First Difference & $-3.2917^{* *}$ & $-5.7551^{* *}$ & $-6.5611^{* *}$ & $-3.1032^{* *}$ & $-5.0459^{* *}$ \\
\hline
\end{tabular}

Results of both ADF and PP tests are showing agreement as the EG shows the stationarity at level while all other four variables are non-stationary at level. It means that series of EG is integrated at level i.e. I(0). $\mathrm{ED}$, tourism demand, inflation, and EXR become stationary at the first difference so, they are I(1). It means that the results are indicating towards the rejection of null hypothesis and it is proved that all series are stationary. Hence, the condition of NARDL is fulfilled i.e. series must be stationary at $\mathrm{I}(0)$ or $\mathrm{I}(1)$. After checking and proving the stationarity of the data, co-integration is checked to determine the significance of long-run estimations. For this purpose, bound testing is applied results of which are presented in table 4. In this test, the null hypothesis is, "there is no co-integration in data" while the alternative hypothesis states, "there is co-integration in data". To reject the null hypothesis, the F-statistics must be greater than upper critical value.

Table 4: Bounds test for co-integration

\begin{tabular}{lcc}
\hline Test & Linear ARDL & Non-Linear ARDL \\
\hline F-Stat & 4.32 & 9.79 \\
Lower Bound 95\% & 2.56 & 2.17 \\
Upper Bound 95\% & 3.49 & 3.21 \\
Decision & Cointegration Exists & Cointegration Exists \\
\hline
\end{tabular}


In the current NARDL model, F-statistics is 9.79, which is greater than upper bound value i.e. 3.21 so, the the results are indicating towards the rejection of null hypothesis and it is found that co-integration exists in the current NARDL model. After examining the co-integration, NARDL results are produced that have been presented in table 5. It is found that adjusted R-square for this NARDL model is 0.725 , which shows that the current NARDL model shows good fit because $72.5 \%$ variation in tourism demand has been explained by other variables of this model. Durbin Watson, heteroscedasticity, and serial correlation LM are diagnostics tests that prove that the current model does not contain any issue of abnormality, heteroscedasticity, and serial correlation. The stability tests are also applied through "cumulative sum" (CUSUM) and "CUSUM square point" for ensuring the stability of long-term as well as short-term parameters as presented in figure 1. It is evident from the figure that all values fall within the critical frontiers at 5\% level of significance. They prove the stability of long-term as well as short-term parameters during the period of 1995-2020.

Table 5: Nonlinear ARDL estimation results.

\begin{tabular}{lllll}
\hline Variable & Coefficient & Std. Error & t-Statistic & Prob. \\
\hline TD $(-1)$ & -0.155 & 0.167 & -2.928 & 0.008 \\
EG_POS & 0.706 & 0.587 & 3.202 & 0.000 \\
EG_NEG & -0.342 & 0.463 & 2.453 & 0.004 \\
ED_POS & -0.337 & 2.117 & -2.048 & 0.049 \\
ED_NEG & -0.068 & 6.045 & -0.507 & 0.619 \\
EXR_POS & -0.446 & 1.021 & -0.437 & 0.668 \\
EXR_NEG & 0.606 & 8.094 & 1.804 & 0.092 \\
INF_POS & 0.783 & 0.185 & 4.215 & 0.000 \\
INF_NEG & -0.367 & 0.223 & -3.643 & 0.002 \\
Constant & -0.619 & 3.426 & -4.180 & 0.009 \\
\hline R-squared & 0.832 & Jarque-Bera (Prob) & 0.239 \\
Adjusted R-squared & 0.725 & Heteroscedasticity (Prob) & 0.565 \\
F-statistic & 7.750 & Durbin-Watson stat & 2.441 \\
Prob(F-statistic) & 0.000 & \multicolumn{2}{l}{ Serial Correlation LM } & 0.201
\end{tabular}

Results of NARDL estimation are proving the presence of asymmetric effects of ED, EG, EXR, and inflation on tourism demand. Results reveal that the increase in EG (EG_POS) has a positive effect on tourism demand (p-value < 0.05). It means that the increase in EG is followed by the positive change in tourism demand. However, the decrease in EG (EG_NEG) causes the inverse effect on tourism demand as the decrease in EG (i.e. negative change in EG) is likely to cause the negative effect of $34.2 \%$ on tourism demand. These results are aligned with Fareed et al. (2018), Brida et al. (2020), Nissan et al. (2011), Isik et al. (2018), He and Zheng (2011), and Kim et al. (2018) because these studies also support the linear or non-linear relationship between EG and tourism demand. These results prove that the tourism demand in Pakistan is likely to be determined by the increase or decrease in its EG.

Results further indicate that the increase in ED (ED_POS) causes the significant negative effect on tourism demand ( $\mathrm{p}$-value $<0.05$ ). It means that the increase in ED causes tourism demand to decrease by $33.7 \%$ in long-run. These results are also consistent with a number of prior studies e.g. (Ahmad et al., 2019; Chung et al., 2018; Haseeb \& Azam, 2020; Otrachshenko \& Bosello, 2017; Zhang et al., 2019) because these studies also support the relationship between ED and tourism demand. However, the decrease in ED does not cause any significant effect on tourism demand in Pakistan as the p-value against this effect is greater than 0.05. The effects of increase or decrease in EXR (i.e. EXR_POS and EXR_NEG) on tourism demand are also insignificant because p-value against both these effects is $>0.05$. The increase in inflation (INF_POS) causes the positive effect on tourism demand which means that the increase in the inflation is followed by the increase in tourism demand by $78.3 \%$ in long run. The decrease in inflation (INF_NEG) has a significant negative effect on tourism demand, which means that the decrease in inflation is followed by the increase in tourism demand in Pakistan by $36.7 \%$ in long run 
(p-value< 0.05). These results are harmonized with findings of Meo et al. (2018) who also reveal the presence of asymmetric association between inflation and tourism demand. Hence, the NARDL estimation of the current study shows that EG, ED, and inflation share the close and asymmetric association with tourism demand of Pakistan.

Figure 1: CUSUM and CUSUMQ test for structural change
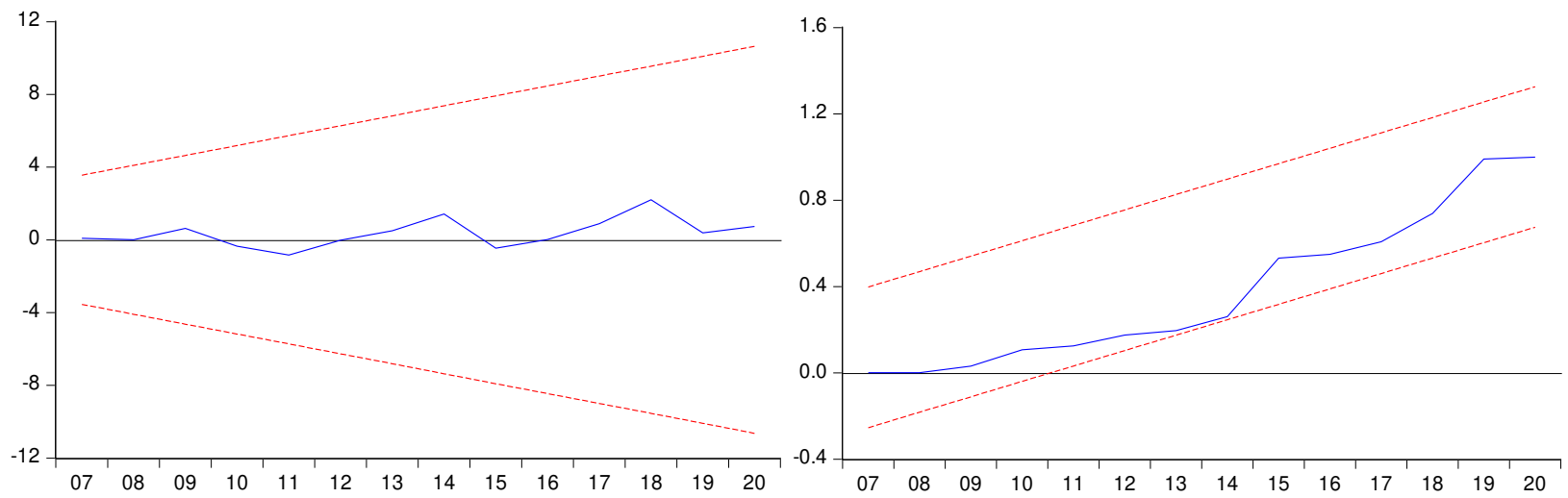

Table 6 presents the results of long-term relationships and coefficients of EG (positive and negative), ED (positive and negative), EXR, and INF. It is evident from table 6 that coefficients size of EG_POS and EG_NEG is not the same. Similarly, the coefficients size of ED_POS and ED_NEG is not the same so, it is proved that asymmetric relationship exists between ED and tourism demand and between EG and tourism

demand.

353 Table 6: Long-run relationship.

\begin{tabular}{lllll}
\hline Variable & Coefficient & Std. Error & t-Statistic & Prob. \\
\hline EG_POS & 0.446 & 0.464 & 4.170 & 0.007 \\
EG_NEG & -0.876 & 0.462 & -4.349 & 0.000 \\
ED_POS & -0.337 & 0.456 & -2.645 & 0.005 \\
ED_NEG & -0.468 & 0.541 & -5.534 & 0.001 \\
EXR & 0.186 & 0.643 & 2.042 & 0.043 \\
INF & 0.122 & 0.743 & 1.994 & 0.050 \\
\hline
\end{tabular}

The presence of asymmetric relationship between variables is further proved through a symmetric Wald test presented in table 7. It is found that the F-statistics against each of the connexion between tourism demand and EG and between tourism demand and ED is greater than F-tabulated and p-value is <0.05. Therefore, the existence of asymmetric relationships between them is confirmed.

Table 7: Presence of asymmetries.

\begin{tabular}{lcc}
\hline Asymmetric Relationship & F-Stat (Prob) & Confirmation? \\
\hline TD $\leftrightarrow$ EG & $4.657(0.000)$ & Yes Confirmed \\
TD $\leftrightarrow$ ED & $5.895(0.000)$ & Yes Confirmed \\
\hline
\end{tabular}
tourism demand by collecting time series data of Pakistan for the time span of 1995-2020. The asymmetric associations have been checked by applying non-linear ARDL modeling on the collected data 
because the positive and negative variations in EG and ED do not cause the tourism demand to vary in a systematic patterns. Therefore, the current study used NARDL modeling to check the asymmetric associations between them. Results of the current study have revealed that there exist the significant asymmetric relationships between ED and tourism demand and between EG and tourism demand. It means that the positive change in EG tends to cause different effect on tourism demand than the effect of negative change in EG. Results suggest that the increase in EG causes the tourism demand of Pakistan to increase while the decrease in EG of Pakistan also causes the tourism demand to increase. Results further show that the increase in ED in Pakistan causes its tourism demand to reduce. However, the decrease in ED of Pakistan did not cause any significant effect on tourism demand. Hence, it is found that the ED and EG are substantial predictors of tourism demand in Pakistan.

\subsection{Implications of Study}

The current study and its findings as well as discussions are likely to be value addition to the theory and practice of tourism. Theoretically, the current empirical findings would enhance the literature regarding the growth-tourism nexus and ED-tourism nexus. As the existing literature seems to provide insufficient empirical evidence and harmonized findings about the relationships of ED and EG with tourism demand so, the current study will contribute to the literature by providing empirical findings from Pakistan. Furthermore, as most of the past studies have examined the linear connection between EG, ED, and tourism demand so, the current NARDL modelling to check these asymmetric relationships will enhance the literature. Practically, the present study is likely to help tourism companies of Pakistan to understand the role of ED and EG in shaping the tourism demand so, they will be able to forecast the tourism demand in better way. Furthermore, the current findings will help them to realize that the ED needs to be reduced in the country for increasing the tourism demand. The current study and its findings will also help policymakers of Pakistan to realize the linkage of EG and ED with the tourism demand of the country so, they can come up with better policies for tourism sector for improving its environmental impacts, economic contribution, and attractiveness for enhancing the tourism demand.

\subsection{Limitations and Future Research Indications}

The current study has a few limitations that can restrict their generalizability and applicability. First, the current study is based on the data of only one country i.e. Pakistan while the patterns of effects of ED and EG on tourism demand can vary in developed countries and even other developing countries. Therefore, these results are not applicable to other countries. Future researchers should assess these asymmetric relationships with panel data to enhance the findings. Another limitation of the current study is about the uni-directionality because the current study only assesses the asymmetric effect of EG and ED on tourism demand while the tourism demand can also affect the EG and ED. Therefore, future researchers should evaluate bidirectional association between them.

\section{Ethical Approval}

All work of this research is completed by the authors and all procedures performed in accordance with the ethical standards.

\section{Consent to Participate.}

Not Applicable

\section{Consent to Publish.}

Not Applicable

\section{Authors Contributions}

All authors contributed to the study main Conceptualization. Data collection and analysis were performed by Muhammad Amir and Azaz Ather. The first draft of the manuscript was written by Amir and Naila Kausar and all authors commented on previous versions of the manuscript. Dr. Siddique and Kamran also lead the whole research process. All authors read and approved the final manuscript.

\section{Funding}

No funding was received for this research.

\section{Competing Interests}


The authors declare that they have no competing interests.

All data generated or analyzed during this study are included available as its supplementary materials.

\section{References}

Adedoyin, F. F., Nathaniel, S., \& Adeleye, N. (2021). An investigation into the anthropogenic nexus among consumption of energy, tourism, and EG: do economic policy uncertainties matter? Environmental Science and Pollution Research, 28(3), 2835-2847.

Ahmad, F., Draz, M. U., Su, L., \& Rauf, A. (2019). Taking the bad with the good: The nexus between tourism and ED in the lower middle-income Southeast Asian economies. Journal of Cleaner Production, 233, 1240-1249.

Anser, M. K., Khan, M. A., Nassani, A. A., Askar, S. E., Abro, M. M. Q., Zaman, K., \& Kabbani, A. (2020). The mediating role of ICTs in the relationship between international tourism and ED: fit as a fiddle. Environmental Science and Pollution Research, 1-15.

Balaguer, J., \& Cantavella-Jorda, M. (2002). Tourism as a long-run EG factor: the Spanish case. Applied Economics, 34(7), 877-884.

Balcilar, M., Van Eyden, R., Inglesi-Lotz, R., \& Gupta, R. (2014). Time-varying linkages between tourism receipts and EG in South Africa. Applied Economics, 46(36), 4381-4398.

Balsalobre-Lorente, D., Driha, O. M., Shahbaz, M., \& Sinha, A. (2020). The effects of tourism and globalization over ED in developed countries. Environmental Science and Pollution Research, 27(7), 7130-7144.

Brida, J. G., Gómez, D. M., \& Segarra, V. (2020). On the empirical relationship between tourism and EG. Tourism management, 81, 104131.

Chung, M. G., Pan, T., Zou, X., \& Liu, J. (2018). Complex interrelationships between ecosystem services supply and tourism demand: general framework and evidence from the origin of three Asian rivers. Sustainability, 10(12), 4576.

Dhaoui, A., \& Bacha, S. (2017). Investor emotional biases and trading volume's asymmetric response: A non-linear ARDL approach tested in S\&P500 stock market. Cogent economics \& finance, 5(1), 1274225.

Eugenio-Martin, J. L., Martín Morales, N., \& Scarpa, R. (2004). Tourism and EG in Latin American countries: A panel data approach. FEEM Working Paper SSRN, 29.

Fareed, Z., Meo, M. S., Zulfiqar, B., Shahzad, F., \& Wang, N. (2018). Nexus of tourism, terrorism, and EG in Thailand: new evidence from asymmetric ARDL cointegration approach. Asia Pacific Journal of Tourism Research, 23(12), 1129-1141.

Granger, C. W., \& Yoon, G. (2002). Hidden cointegration. U of California, Economics Working Paper(2002-02).

Haseeb, M., \& Azam, M. (2020). Dynamic nexus among tourism, corruption, democracy and ED: a panel data investigation. Environment, Development and Sustainability, 1-19.

Haseeb, M., Hassan, S., Azam, M., \& Suryanto, T. (2018). The dynamics of governance, tourism and ED: the world evidence. International Journal of Global Environmental Issues, 17(4), 340-363.

He, L.-h., \& Zheng, X.-g. (2011). Empirical analysis on the relationship between tourism development and EG in Sichuan. Journal of Agricultural Science, 3(1), 212.

Isik, C., Dogru, T., \& Turk, E. S. (2018). A nexus of linear and non-linear relationships between tourism demand, renewable energy consumption, and EG: Theory and evidence. International Journal of Tourism Research, 20(1), 38-49.

Jalil, A., Mahmood, T., \& Idrees, M. (2013). Tourism-growth nexus in Pakistan: Evidence from ARDL bounds tests. Economic modelling, 35, 185-191.

Kim, J., Lee, C.-K., \& Mjelde, J. W. (2018). Impact of economic policy on international tourism demand: the case of Abenomics. Current Issues in Tourism, 21(16), 1912-1929. 
Leitão, N. C., \& Balsalobre-Lorente, D. (2021). The Effects of Tourism, EG and Renewable Energy on Carbon Dioxide Emissions Strategies in Sustainable Tourism, EG and Clean Energy (pp. 67-87): Springer.

Manzoor, F., Wei, L., \& Asif, M. (2019). The contribution of sustainable tourism to EG and employment in Pakistan. International Journal of Environmental Research and Public Health, 16(19), 3785.

Martins, L. F., Gan, Y., \& Ferreira-Lopes, A. (2017). An empirical analysis of the influence of macroeconomic determinants on World tourism demand. Tourism management, 61, 248-260.

Meo, M. S., Chowdhury, M. A. F., Shaikh, G. M., Ali, M., \& Masood Sheikh, S. (2018). Asymmetric impact of oil prices, exchange rate, and inflation on tourism demand in Pakistan: new evidence from nonlinear ARDL. Asia Pacific Journal of Tourism Research, 23(4), 408-422.

Muhtaseb, B. M., \& Daoud, H.-E. (2017). Tourism and EG in Jordan: Evidence from linear and nonlinear frameworks. International Journal of Economics and Financial Issues, 7(1).

Naradda Gamage, S. K., Hewa Kuruppuge, R., \& Haq, I. u. (2017). Energy consumption, tourism development, and ED in Sri Lanka. Energy Sources, Part B: Economics, Planning, and Policy, 12(10), 910-916.

Nissan, E., Galindo, M.-A., \& Méndez, M. T. (2011). Relationship between tourism and EG. The Service Industries Journal, 31(10), 1567-1572.

Otrachshenko, V., \& Bosello, F. (2017). Fishing for answers? Impacts of marine ecosystem quality on coastal tourism demand. Tourism Economics, 23(5), 963-980.

Panopoulou, E., \& Pittis, N. (2004). A comparison of autoregressive distributed lag and dynamic OLS cointegration estimators in the case of a serially correlated cointegration error. The Econometrics Journal, 7(2), 585-617.

Paramati, S. R., Alam, M. S., \& Chen, C.-F. (2017). The effects of tourism on EG and CO2 emissions: a comparison between developed and developing economies. Journal of Travel Research, 56(6), 712-724.

Pavlic, I., Svilokos, T., \& Tolic, M. S. (2015). Tourism, real effective exchange rate and EG: Empirical evidence for Croatia. International Journal of Tourism Research, 17(3), 282-291.

Raza, S. A., Qureshi, M. A., Ahmed, M., Qaiser, S., Ali, R., \& Ahmed, F. (2021). Non-linear relationship between tourism, EG, urbanization, and ED: evidence from smooth transition models. Environmental Science and Pollution Research, 28(2), 1426-1442.

Raza, S. A., Sharif, A., Wong, W. K., \& Karim, M. Z. A. (2017). Tourism development and ED in the United States: evidence from wavelet-based analysis. Current Issues in Tourism, 20(16), 17681790.

Rehman, A., Ma, H., Irfan, M., Ahmad, M., \& Traore, O. (2020). Investigating the Influence of International Tourism in Pakistan and Its Linkage to EG: Evidence From ARDL Approach. Sage Open, 10(2), 2158244020932525.

Risso, W. A., Barquet, A., \& Brida, J. G. (2010). Causality between EG and tourism expansion: empirical evidence from Trentino-Alto Adige. Tourismos: an international multidisciplinary journal of tourism, 5(2), 87-98.

Samimi, A. J., Sadeghi, S., \& Sadeghi, S. (2011). Tourism and EG in developing countries: P-VAR approach. Middle-East Journal of Scientific Research, 10(1), 28-32.

Shafiullah, M., Okafor, L. E., \& Khalid, U. (2019). Determinants of international tourism demand: Evidence from Australian states and territories. Tourism Economics, 25(2), 274-296.

Sharif, A., Godil, D. I., Xu, B., Sinha, A., Khan, S. A. R., \& Jermsittiparsert, K. (2020). Revisiting the role of tourism and globalization in ED in China: Fresh insights from the quantile ARDL approach. Journal of Cleaner Production, 272, 122906.

Sokhanvar, A. (2019). Does foreign direct investment accelerate tourism and EG within Europe? Tourism Management Perspectives, 29, 86-96.

Suresh, J., \& Senthilnathan, S. (2014). Relationship between tourism and EG in Sri Lanka. Published as the 7th chapter of a book entitled "Economic Issues in Sri Lanka" compiled by Dr. S. Vijayakumar, 115-132. 
513 Tang, C. F., \& Ozturk, I. (2017). Is tourism a catalyst of growth in Egypt? Evidence from Granger noncausality and the generalised variance decomposition analysis. Anatolia, 28(2), 173-181.

515 Tavares, J. M., \& Leitao, N. C. (2017). The determinants of international tourism demand for Brazil. Tourism Economics, 23(4), 834-845.

Zhang, Y., Khan, S. A. R., Kumar, A., Golpîra, H., \& Sharif, A. (2019). Is tourism really affected by logistical operations and ED? An empirical study from the perspective of Thailand. Journal of Cleaner Production, 227, 158-166. 
Figures
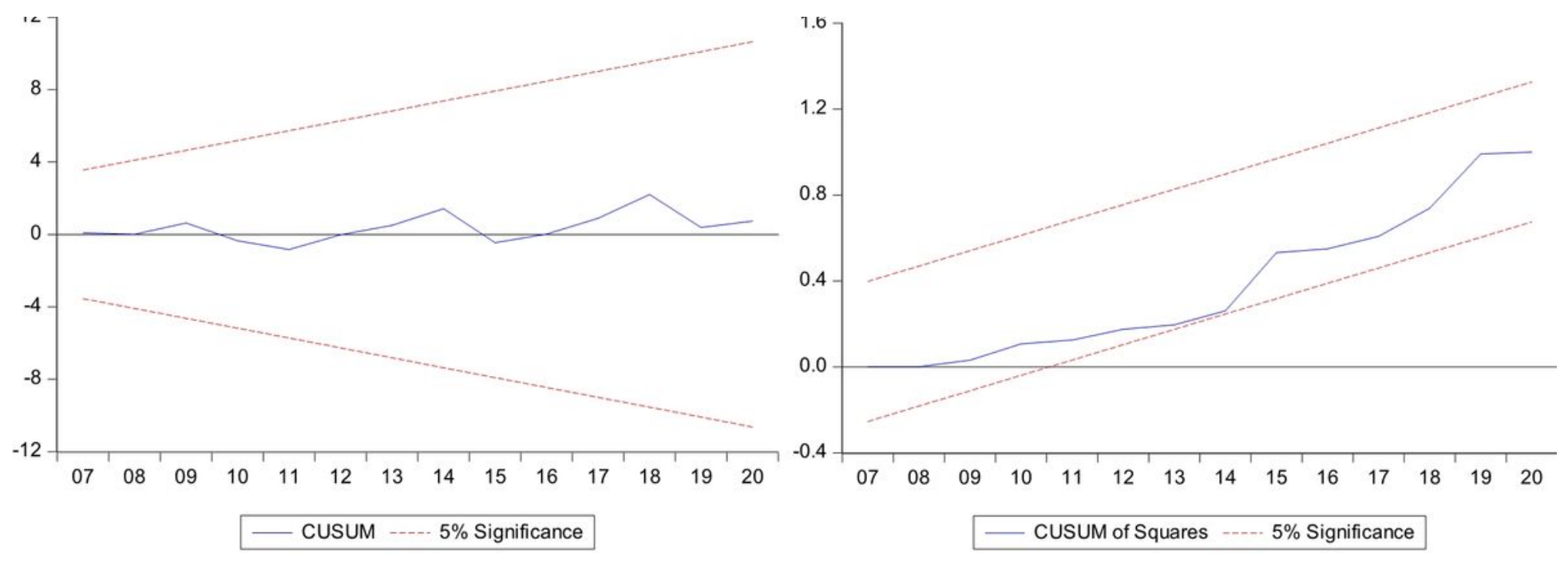

Figure 1

CUSUM and CUSUMQ test for structural change

\section{Supplementary Files}

This is a list of supplementary files associated with this preprint. Click to download.

- DataSet.xlsx 